(2) Open Access Full Text Article

REVIEW

\title{
Contact lens associated microbial keratitis: practical considerations for the optometrist
}

This article was published in the following Dove Press journal:

Clinical Optometry

29 January 2016

Number of times this article has been viewed

\author{
Aaron B Zimmerman \\ Alex D Nixon \\ Erin M Rueff \\ College of Optometry, The Ohio State \\ University, Columbus, $\mathrm{OH}$, USA
}

\begin{abstract}
Microbial keratitis (MK) is a corneal condition that encompasses several different pathogens and etiologies. While contact lens associated MK is most often associated with bacterial infections, other pathogens (fungi, Acanthamoeba species, etc) may be responsible. This review summarizes the risk factors, microbiology, diagnostic characteristics, and treatment options for all forms of contact lens-related MK.
\end{abstract}

Keywords: corneal ulcer, fungal keratitis, bacterial keratitis, Acanthamoeba, Fusarium, Pseudomonas

\section{Introduction}

There are approximately 38 million individuals wearing contact lenses in the United States. ${ }^{1}$ Contact lens wear significantly increases the risk of ocular complications, specifically microbial keratitis (MK), which is the most severe complication and is vision threatening. ${ }^{2} \mathrm{MK}$ is a term that includes bacterial keratitis (BK), fungal keratitis (FK), and Acanthamoeba keratitis (AK) (Table 1). Geographically, the causes of MK differ. In non-Westernized countries, trauma is the leading cause of $\mathrm{MK}^{3,4}$ whereas in Westernized countries, contact lens wear is equal to or often exceeds trauma as the most significant cause. ${ }^{5-7}$ This review describes the incidence, risk factors, and pathogenesis of contact lens associated MK and the practitioner's role in properly diagnosing, culturing, and managing these severe complications.

\section{Incidence}

The first large epidemiological study on contact lens-related MK was published in 1989, and the incidence rate of MK among individuals wearing lenses in the daily wear modality was 4.1 per 10,000 individuals per year (Table 2).$^{8}$ In 2008, Stapleton et al reported an annual MK incidence rate in daily wear of 1.9 per 10,000 wearers, ${ }^{9}$ which is consistent with other studies. ${ }^{10-12}$

Compared with daily wear, overnight (extended wear, EW) use of soft contact lenses is associated with a higher risk of MK. EW, irrespective of material type, has been shown to be the primary factor for corneal infection with an annual incidence of approximately 20 per 10,000. ${ }^{9,13}$ Interestingly, sporadic or occasional EW has been shown to be a more significant MK risk factor than continuous wear. ${ }^{14}$ The introduction of highly oxygen-permeable silicone hydrogel materials has not provided the anticipated decrease in MK associated with EW. The incidence of MK and corneal inflammatory events $^{15}$ with silicone hydrogel EW has been shown to be the same ${ }^{14,16}$ or $_{\text {greater }}{ }^{17}$ than lower oxygen permeability hydrogel materials. While silicone hydrogel materials
Correspondence: Aaron B Zimmerman College of Optometry, The Ohio State University, A317 Starling Loving Hall, 338 West IOth Avenue, Columbus, $\mathrm{OH}$ 43210 , USA

$\mathrm{Tel}+\mathrm{I} 6142476188$

Fax +I 6142476626

Email zimmerman.178@osu.edu 
Table I Types of microbial keratitis and the primary risk factors for acquiring these infections in Westernized countries

\begin{tabular}{llll}
\hline \% MK due to: & Bacterial & Fungal & Acanthamoeba \\
\hline Contact lens & $33.7^{7}-50.3^{5}$ & $25^{124}-29.2^{33}$ & $85^{84}-93^{86}$ \\
Trauma & $15^{5}-36.4^{7}$ & $8.3^{33}-26^{124}$ & $7^{86}-15^{84}$ \\
Ocular surface disease & $6.9^{7}-21.3^{5}$ & $29^{124}-41.7^{33}$ & NR \\
Other $^{\mathrm{a}}$ & $13.4^{5}-23^{7}$ & $16.7^{33}-20^{124}$ & $\mathrm{NR}$ \\
\hline
\end{tabular}

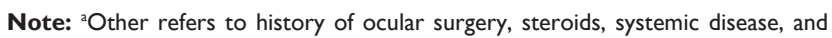
unknown risk factors.

Abbreviation: MK, microbial keratitis; NR, not reported.

reduce hypoxia-related complications, they do not eliminate exposure to pathogenic organisms. It has been suggested that silicone hydrogel materials may alter epithelial homeostasis, resulting in mechanical stress that makes the cornea more susceptible to inflammatory and/or infectious events. ${ }^{17}$

The incidence of MK with gas-permeable (GP) materials ranges between $0.8^{10}$ and $4.0^{8}$ per 10,000 per year. These reported rates included both daily wear and EW. Orthokeratology, a form of GP lens vision correction, involves wearing lenses overnight to reshape the cornea and correct myopia. The annual rate of $\mathrm{MK}$ associated with orthokeratology is estimated to be 7.7 per 10,000. ${ }^{18}$ In Asian countries, orthokeratology-related MK has been shown to be most common in areas with more prevalent myopia. ${ }^{19}$ It has been suggested that this higher prevalence may be due to poor regulation in these areas. ${ }^{20}$ Regardless of wearing soft or GP contact lenses, EW significantly increases the risk of contracting MK compared with daily wear.

\section{Risk factors}

MK in contact lens wearers is typically associated with noncompliant or unhygienic contact lens practices. Many of these risky behaviors which include $\mathrm{EW},{ }^{2,8-10}$ poor storage case hygiene and infrequent case replacement, ${ }^{9,21,22}$ smoking, ${ }^{2,8-10,23}$ lack of hand washing, ${ }^{10}$ and purchasing lenses on the internet ${ }^{9}$ are all modifiable. Nonmodifiable risk factors are wearing lenses for less than 6 months, ${ }^{9}$ male sex, ${ }^{8,24}$ socioeconomic status, ${ }^{9}$ and possibly a genetic predisposition. ${ }^{25,26}$
Lens-related MK risk factors include cosmetic lenses, as these lenses are often not prescribed by an eye care professional and therefore, patients have less knowledge of proper lens care. ${ }^{27}$ Daily disposable lenses do not eliminate the risk of $\mathrm{MK},{ }^{9,13}$ however, there may be a lower risk of vision loss when compared with planned replacement. ${ }^{9,13}$ The type of contact lens disinfection system used has been found to modify the risk of $\mathrm{MK},{ }^{28}$ and specific brands were responsible for the $\mathrm{FK}^{29}$ and $\mathrm{AK}^{30}$ outbreaks.

FK and AK cases have additional risk factors that need to be ruled out when MK is present. FK associated with vegetative trauma and/or ocular surface disease is most common in tropical and subtropical climates. ${ }^{31,32}$ Trauma or corneal compromise caused by contact lens wear has also been suggested as a risk factor. ${ }^{31,33}$ Candida species tend to infect corneas that are comprised due to ocular surface disease and/ or systemic immunodeficiency ${ }^{31,34}$ and are more common in temperate climates. ${ }^{31,34}$

Acanthamoeba associated MK, while relatively rare, ${ }^{35}$ often results in severe vision loss due to misdiagnosis. ${ }^{36}$ Because of the frequent misdiagnosis of this condition, longer duration of symptoms and history of antibiotic use have been listed as risk factors. ${ }^{36}$ As mentioned above, exposure to infected water is a well-known risk factor for Acanthamoeba infection..$^{28}$ This exposure may occur when contact lenses are cleaned/stored in tap water, or when a patient is exposed to bodies of water that could be infected (lakes, hot tubs, etc). ${ }^{28,37}$

\section{Pathogenesis Inherent protective mechanisms and contact lens-induced alterations}

A healthy corneal surface is not susceptible to microbial infection. Chronic ocular surface disease, corneal trauma, ocular surgery, and contact lens wear increase the cornea's susceptibility to infection. The mechanisms of contact lensrelated corneal infection are not fully understood; however, several models exist for bacterial, fungal, and protozoan infections.

Table 2 Annual incidence of contact lens-related bacterial, fungal, and protozoan keratitis

\begin{tabular}{llll}
\hline Lens type & Bacterial & Fungal & Acanthamoeba \\
\hline Overall incidence & $4^{9} / 10,000$ & $\sim 1 / 50,000^{119, a}$ & $\mathrm{I}-33 / \mathrm{million}^{35}$ \\
Soft lenses (daily wear) & $1.9^{9}-4.1^{8} / 10,000$ & $\mathrm{NR}$ & $\mathrm{NR}$ \\
Soft lenses (extended wear) & $19.5^{9} / 10,000$ & $\mathrm{NR}$ & $\mathrm{NR}$ \\
$\quad$ Hydrogel & $9.3^{10}-20.9^{8} / 10,000$ & $\mathrm{NR}$ & $\mathrm{NR}$ \\
Silicone hydrogel & $20.9^{14}-25.4^{9} / 10,000$ & $\mathrm{NR}$ & $\mathrm{NR}$ \\
Gas-permeable (daily wear) & $0.8^{10}-4.0^{8} / 10,000$ & $\mathrm{NR}$ & $\mathrm{NR}$ \\
$\quad$ Orthokeratology & $7.7^{18} / 10,000$ & $\mathrm{NR}$ & $\mathrm{NR}$ \\
\hline
\end{tabular}

Note: ${ }^{a}$ Estimation calculated from Konda et al ${ }^{119}$ which stated $5 \%$ of all contact lens microbial keratitis is fungal.

Abbreviation: NR, not reported. 
The non-contact lens exposed cornea easily resists microbes from "sticking" to the ocular surface through several inherent protective mechanisms employed by the tear fluid and corneal epithelium..$^{38}$ The tear fluid, along with blinking, clears pathogens from the cornea and contains antimicrobial components such as lysozyme and lactoferrin. ${ }^{39}$ The epithelial cells also produce peptides and mucins that are inherently antimicrobial. ${ }^{40}$ The epithelial tight junctions serve as a physical barrier to microbes, however, even when the superficial junctions are damaged, Pseudomonas cannot traverse the protective anterior limiting lamina (Bowman's membrane) to the stroma. ${ }^{41}$ This suggests that superficial fluorescein staining does not lead to MK. ${ }^{42}$

Contact lens wear disrupts some of these innate defenses and renders the cornea more susceptible to infection. Lens wear, regardless of oxygen transmissibility, has been shown to decrease epithelial mitosis, differentiation, ${ }^{43}$ and exfoliation. ${ }^{44}$ These processes create a stagnant epithelium and render the cornea more susceptible to infection. Hypoxic conditions have been shown to decrease epithelial exfoliation, but hypoxia alone does not increase Pseudomonas binding. ${ }^{45}$ Hypoxia can lead to increased Pseudomonas corneal binding, but only when a contact lens is also present. ${ }^{46}$

Contact lens wear has also been shown to mechanically damage the epithelium, resulting in punctate epithelial erosions. ${ }^{47}$ Interestingly, though the surface damage is worse with a GP, there is increased Pseudomonas epithelial binding with soft lenses from reduced tear exchange beneath the contact lens. ${ }^{47}$ Planktonic, or free floating, bacteria adhere to the surface of the contact lens and can form virulent biofilms which are less susceptible to the normal antimicrobial defense mechanisms of the tears and epithelium..$^{42}$ Biofilms on the posterior contact lens surface place bacteria in close proximity to the epithelium and these microbes cannot be easily cleared away, creating a stagnant tear environment. ${ }^{48}$

\section{Bacterial keratitis model}

The majority of contact lens-related bacterial ulcers are due to Pseudomonas, ${ }^{6,49}$ and the stagnant post-lens tear environment may allow for Pseudomonas to "stick" to the corneal epithelium which must happen in order for an infection to develop..$^{50}$ Pseudomonas adheres to the corneal epithelium via specific receptors expressed on the outer cell membrane. ${ }^{51}$ Specific to Pseudomonas, there is an invasive phenotype, exoenzyme $\mathrm{S}$ (exoS) gene, and a cytotoxic phenotype, exoenzyme $U$ (exoU) gene. The invasive form enters epithelial cells via lipid rafts, replicates intracellularly, and eventually causes host cell death. ${ }^{50}$ Interestingly, the presence of Pseudomonas alone does not trigger lipid raft development, but a low oxygen transmissible lens also is necessary. The cytotoxic phenotype is associated with severe corneal inflammation and tissue damage due to the extracellular injection of a potent cytoxin..$^{52}$ Choy et al suggested that with contact lens wear, the cytoxic phenotype is isolated more often than the invasive phenotype ${ }^{53}$ however, a recent article suggests otherwise. ${ }^{54}$

Regardless of the phenotypes listed above, Pseudomonas species have additional virulence factors such as adhesins, ${ }^{55}$ flagella, ${ }^{56}$ several forms of toxins, ${ }^{57}$ and have even been capable of metabolizing some antibiotics. ${ }^{58}$ They also employ auxiliary genetic code in the form of plasmids. ${ }^{57}$ These factors allow the bacterium to be extremely dynamic and potentially evade host defense mechanisms which compounds tissue damage and can result in worse visual outcomes.

\section{Fungal keratitis model}

In the United States, FK most often occurs from agricultural related trauma, contact lens wear, and ocular surface disease ${ }^{59}$ Filamentous fungi, such as Fusarium and Aspergillus, tend to be most often associated with contact lens wear and trauma, while those with ocular surface disease are more prone to yeasts. ${ }^{59}$

Contact lens-related FK likely results from fungal biofilms, which can be firmly attached to the posterior side of the lens or even extend into the lens matrix. ${ }^{60}$ Using a murine model, it has been shown that hyphae from Fusarium or Aspergillus in contact with the corneal epithelium may disrupt epithelial integrity ${ }^{61}$ If the epithelial integrity is affected, then hyphae have the capability of breaching the basement membrane and the anterior limiting lamina and ultimately reaching the stroma. ${ }^{62}$ Once in the stroma, the hyphae can continue to extend through the stroma and in some cases can perforate the cornea reaching the anterior chamber. ${ }^{62}$ The extending hyphae result in the feathery border appearance that is classically seen with FK..$^{62}$ Neutrophils are recruited to the site and release proteolytic enzymes ${ }^{61}$ and reactive oxygen species ${ }^{64}$ which eradicate the fungus, but can also cause substantial collateral tissue damage. The cumulative inflammation may also trigger the development of a hypopyon and an endothelial plaque..$^{59,62}$

\section{Acanthamoeba keratitis model}

According to the Centers for Disease Control and Prevention, Acanthamoeba is commonly found in soil, water, and air. ${ }^{65}$ Contact lens-wearing individuals who expose their lenses to water through swimming, hot tubs, trauma with contaminated 
water, or care for their lenses with water are at greater risk of infection.

The largest risk factor for contact lens-related $\mathrm{AK}$ is poor compliance with lens care which leads to subsequent biofilm formation. ${ }^{66}$ These biofilms, such as those formed by Pseudomonas aeruginosa provide a nutrient-rich environment for Acanthamoeba trophozoites to thrive. ${ }^{66}$ Once Acanthamoeba is present on the surface of the contact lens, the cornea is at increased risk of infection. ${ }^{66}$ Khan et al found that for Acanthamoeba to bind to and develop a corneal infection, a previous insult to the epithelial tissue must be present. ${ }^{67}$ Omana-Molina et al have recently found that Acanthamoeba are actually capable of binding to intact epithelium. ${ }^{68}$

Acanthamoeba trophozoites are likely present during epithelial binding, because the cystic form shows minimal binding capability. ${ }^{69}$ The trophozoites adhere to the epithelium using mannose-binding protein ${ }^{70}$ and other laminin-binding proteins. ${ }^{69}$ Contact lenses have been shown to stimulate glycoprotein expression, ${ }^{71}$ and the mannosebinding protein may have greater tendency to bind to the epithelium. ${ }^{72}$ Once bound to the corneal epithelium, the trophozoites use phagocytosis for nutrition and secrete toxins, such as serine proteases, collagenases, and stimulate the activity of cytotoxic matrix metalloproteinases, which creates a cytopathic effect. ${ }^{73}$ The cytopathic effect includes killing host cells by phagocytosis, apoptosis, or cytolysis, followed by degradation of the epithelial basement membrane and anterior limiting lamina, and subsequent migration into the corneal stroma. Interestingly, Acanthamoeba does not typically breach the corneal endothelium ${ }^{74}$ and this is thought to be due to an intense response from neutrophils. ${ }^{75}$

When the trophozoites experience a change in $\mathrm{pH}$, temperature, lack of nutrition, or chemicals they can form doublewalled cysts. ${ }^{76}$ Cysts are very difficult to treat and have been found in postinfected corneas 31 months after onset and in some cases likely longer. ${ }^{77}$ The corneal infection is not truly gone until all the trophozoites and cysts have been removed from the cornea. ${ }^{77}$

\section{Diagnosis}

\section{Patient history}

Proper diagnosis of $\mathrm{MK}$ is based on a combination of patient symptoms, pertinent ocular history, clinical examination, and culturing. The patient's history and symptoms provide us valuable clues regarding the etiology of the keratitis. Trauma due to vegetative debris often is associated with
FK while a history of hot tub use or contact with stagnant water suggests AK. Patients with a history of contact lens wear are at risk for any form of MK and should be further questioned to elucidate potential risk factors such as overnight wear, poor contact lens, or case hygiene, swimming in contact lenses, or using water for cleaning, disinfection, or storage.

\section{Bacterial keratitis}

Individuals with BK will often experience significant pain, photophobia, and likely enter the clinic with reduced visual acuity (Table 3 ). The onset of symptoms often occurs quickly. There are several common slit lamp characteristics found with BK. A corneal infiltrate, or multiple corneal infiltrates are found in every case, while the size of the infiltrate can vary dramatically. ${ }^{5}$ An infiltrate that is greater than or equal to $1 \mathrm{~mm}$ in width is often considered infectious. ${ }^{78}$ Depending on the severity of the infection, infiltrate depth can vary with the majority $(77 \%)$ being confined to the anterior one-third of the stroma. ${ }^{5}$ The epithelium overlying the infiltrate is often absent, and the tissue may appear slightly excavated. ${ }^{79}$ A noninfectious ulcer often has an overlying staining area that is smaller than the infiltrate diameter. ${ }^{79}$ Anterior chamber inflammation may be present with hypopyon developing between $6.1 \%{ }^{5}$ and $55 \%{ }^{36}$ of the time. The bulbar conjunctiva is often diffusely injected, and the discharge can range from a watery to a mucopurulent consistency. ${ }^{79}$ In addition to the ocular surface changes, the eyelids may also be edematous. $^{79}$

\section{Fungal keratitis}

The patient history and onset of symptoms is essential when diagnosing FK. Fungi need time to grow, so symptoms may be delayed for 5-10 days. ${ }^{62} \mathrm{AK}$ and BK typically will have a faster onset of symptoms.

The clinical appearance of FK depends on whether the infection is due to filamentous fungi such as Fusarium and Aspergillus or a yeast such as Candida. Corneal infections due to Candida often resemble $\mathrm{BK}$ as there is a round or ovalish epithelial defect with surrounding inflammation. ${ }^{80}$ Mycotic keratitis due to Fusarium or Aspergillus will be associated with "feathery" edges, elevated slough, ${ }^{62,81}$ and satellite infiltrates. ${ }^{82}$ A hypopyon can develop ${ }^{81}$ as can an endothelial plaque. ${ }^{83}$ Thomas et al compared the slit lamp signs of patients with fungal and BK, and found that serrated margins, raised slough, and satellite lesions were more often associated with FK, whereas BK had a greater frequency of hypopyon and anterior chamber flare. ${ }^{81}$ 
Table 3 Clinical characteristics of the different forms of microbial keratitis

\begin{tabular}{|c|c|c|c|}
\hline Clinical characteristics & Bacterial keratitis & Fungal keratitis & Acanthamoeba keratitis \\
\hline Onset of symptoms & Rapid & Several days ${ }^{62}$ & Rapid \\
\hline History & $\begin{array}{l}\text { Contact lens wear, trauma, } \\
\text { and ocular surface disease }\end{array}$ & $\begin{array}{l}\text { Vegetative trauma, contact lens } \\
\text { wear, and ocular surface disease }\end{array}$ & $\begin{array}{l}\text { Water exposure and contact lens wear; } \\
\text { may have been treated prior as herpes simplex }\end{array}$ \\
\hline $\begin{array}{l}\text { Key differentiating } \\
\text { slit lamp findings }{ }^{a}\end{array}$ & $\begin{array}{l}\text { Round or oval shaped lesion, } \\
\text { and anterior chamber flare }\end{array}$ & $\begin{array}{l}\text { Feathery borders, satellite } \\
\text { lesion, and necrotic slough } \\
\text { *Yeast infection mirrors }^{81} \\
\text { bacterial ulcers }\end{array}$ & $\begin{array}{l}\text { Early: }{ }^{85} \text { epithelial disruption without stromal } \\
\text { disease and perineural infiltrates } \\
\text { Late: }{ }^{: 5,86,103} \text { ring infiltrate }\end{array}$ \\
\hline Treatments & $\begin{array}{l}\text { Fluoroquinolones, chloro- } \\
\text { fluoroquinolones, and } \\
\text { fortified antibiotics }\end{array}$ & $\begin{array}{l}\text { Natamycin, voriconazole, } \\
\text { and amphotericin }\end{array}$ & $\begin{array}{l}\text { Polyhexamethylene biguanide, chlorhexidine, } \\
\text { propamidine, neomycin, and oral voriconazole }\end{array}$ \\
\hline Healing time (days) & $3.5-6.8^{98, \mathrm{~b}}$ & $31-40^{102}$ & $\begin{array}{l}140-547^{103,127,129} \\
\text { Steroid: }{ }^{103} \mid 63 \pm 50^{c} \\
\text { No steroid: }{ }^{103} 94 \pm 45^{c}\end{array}$ \\
\hline $\begin{array}{l}\text { Percentage with visual } \\
\text { acuity worse than } 20 / 30\end{array}$ & $13.9^{9}$ & $30^{129}$ & 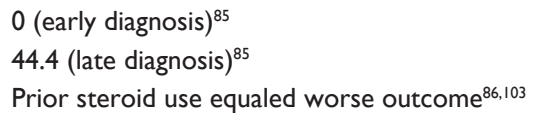 \\
\hline $\begin{array}{l}\text { Percentage requiring } \\
\text { penetrating keratoplasty }\end{array}$ & $0^{9}-13^{131}$ & $16.8^{124}$ & $20-32^{87}$ \\
\hline Cost $^{7}$ (US\$) & $\mid, 200-1,800$ & 4,648 & 5,697 \\
\hline
\end{tabular}

Notes: aAll conditions will likely have redness, photophobia, discharge, and significant pain. ${ }^{\mathrm{b}}$ For ulcers ranging from $>\mathrm{I} \mathrm{mm}{ }^{2}$ to $<4 \mathrm{~mm}{ }^{2}$. ${ }^{\mathrm{D}} \mathrm{Data}$ presented as mean \pm standard deviation.

\section{Acanthamoeba keratitis}

The classic clinical signs of AK are a ring infiltrate and perineuritis; $;{ }^{84-86}$ however, the clinician must understand that these signs are not always present. Two recent retrospective studies have found that perineuritis was present in $20.7 \%$ and $21.6 \%,{ }^{86}$ whereas the ring infiltrate was found in $27.6 \%{ }^{85}$ and $29.3 \%{ }^{86}$ The early clinical signs tend to be a nonspecific epitheliopathy, pseudo-dendrites, subepithelial infiltrates, and in some cases perinueral infiltrates. ${ }^{84,85}$ As the disease progresses, the progression to a ring infiltrate and uveitis are more likely to be identified ${ }^{84}$ If the disease is diagnosed early, usually within the first few weeks, the disease can be confined to the epithelium or anterior stroma and visual outcomes are substantially better compared with a late diagnosis. ${ }^{85}$

Confocal microscopy is a technique that has been shown to assist with diagnosing the condition. ${ }^{86} \mathrm{Hau}$ et al presented confocal microscopy images from culture positive specimens to cornea specialists masked to the tissue diagnosis and asked them to provide a clinical diagnosis. ${ }^{87}$ Relying on confocal microscopy alone resulted in a sensitivity range of $27.9 \%-55.8 \%$ and specificity range of $42.1 \%-84.2 \% .{ }^{87}$ When using confocal microscopy in addition to clinical characteristics and objective findings, Tu et al found the sensitivity to be $90.6 \%$ and a specificity of $100 \% .{ }^{88} \mathrm{Confocal}$ microscopy alone is not reliable enough to diagnose $\mathrm{AK}$, but when combined with clinical findings and culturing (positive culture rates are as high as $88 \%$ ), it can aid in properly diagnosing the condition. ${ }^{86}$

\section{Treatment Bacterial keratitis}

Due to the inherent delay in accessing culture results, the clinician must initiate treatment empirically. Studies have shown that a single fluoroquinolone is as effective as fortified preparations in treating BK. ${ }^{89-91}$ It should be noted that only ciprofloxacin $0.3 \%$, ofloxacin $0.3 \%$, and levofloxacin $1.5 \%$ have US Food and Drug Administration approval for treating $\mathrm{BK}^{92}$ although use of fourth generation fluoroquinolones as monotherapy is quite common ${ }^{89}$ Due to increased microbial resistance to fluoroquinolones, ${ }^{93}$ specifically with methicillinresistant Staphylococcus aureus, ${ }^{94}$ some advocate for initial empirical monotherapy use of the chlorofluoroquinolone, besifloxacin $0.6 \% .{ }^{95,96}$ If methicillin-resistant Staphylococcus aureus is identified through culturing or Gram stain, the treatment may be modified to include a more potent agent such as fortified vancomycin. ${ }^{97}$

The antibiotic must be applied to the ocular surface frequently. In two studies, the initial treatment consisted of a drop every hour around the clock. ${ }^{4,89}$ With severe ulcers the eye drops can be instilled every 5-15 minutes for first hour followed by hourly or half-hourly application..$^{92} \mathrm{BK}$ resolution depends on the initial size of the ulcer, but most re-epithelialize within 3.5-7 days. ${ }^{98}$

In addition to an antibiotic, a cycloplegic agent can be used to minimize photophobia and risk of posterior synechiae. ${ }^{92}$ The role of corticosteroids with BK is more controversial and 
the Steroids for Corneal Ulcer study found no improvement in clinical outcome in the steroid group versus the placebo group. ${ }^{99}$ Although there was no overall benefit, there was also no evidence of a reduced visual outcome. ${ }^{99}$ When limiting the sample to only the most severe cases, steroids did provide a slight clinical benefit. ${ }^{99}$ For the clinician, if BK is suspected, the application of a steroid should only commence if clinical signs are improving, which suggests that the selected antibiotic is effective against the offending microbe.

\section{Fungal keratitis}

The only US Food and Drug Administration approved ophthalmic antifungal medication is 5\% natamycin, which is commercially labeled as Natacyn (Alcon Inc., Fort Worth, TX, USA). A recent worldwide survey on FK treatment practice patterns found that natamycin is the most frequently used antifungal for filamentous fungi. ${ }^{100}$ Amphotericin and voriconazole were the next most common. For infections caused by yeast, amphotericin was the most common followed by natamycin. ${ }^{100}$ Overall, respondents reported use of oral antifungals "always" (10\%), "most of the time" (27\%), "sometimes" (55\%), and "never" (8\%). ${ }^{100}$

Natamycin and amphotericin are polyenes which irreversibly bind to ergosterol and increase fungal cell wall permeability. ${ }^{101}$ Voriconazole is a triazole, and this inhibits ergosterol synthesis. ${ }^{100}$ The Mycotic Ulcer Treatment Trial compared the performance of these two medications and found that natamycin overall had better visual outcomes and faster resolution when compared with voriconazole. ${ }^{102}$ For Fusarium keratitis, natamycin significantly improved vision outcomes and reduced the risk of perforation. For nonFusarium FK, the two medications performed similarly. ${ }^{102}$

\section{Acanthamoeba keratitis}

There are no approved amoebicidal agents at this time. ${ }^{84}$ The typical medications used for AK can include biguanides or diamidines. The two biguanide agents are polyhexamethylene biguanide $0.02 \%-0.06 \%$ and chlorhexidine $0.02 \%-0.2 \%{ }^{84}$ Biguanides damage the cytoplasmic membrane which results in a loss of cellular components. ${ }^{84}$ The diamidines induce structural changes to the cellular membrane altering permeability, ${ }^{84}$ and the typical agents are propamidine $0.1 \%$ and hexamidine $0.1 \%$. Some centers still use neomycin, but not as monotherapy. ${ }^{85,103}$ The vast majority of corneal specialists $(93.9 \%)$ use a combination of agents. ${ }^{104}$ Oral voriconazole, an antifungal, can have an ameobicidal effect by binding ergosterol - which is present in the cell membrane of fungi and Acanthamoeba. ${ }^{105}$ Steroids are reportedly used during the course of Acanthamoeba treatment, but their role is controversial. ${ }^{104}$

Nonpharmaceutical treatments for MK cases that are not responding to topical medication can include penetrating or lamellar keratoplasties of the infected cornea, ${ }^{106}$ which are known as "hot corneal grafts". The use of corneal crosslinking for $\mathrm{MK}$ is becoming more common ${ }^{107-109}$ and can be effective in eradicating offending microbes. Amniotic membranes can also be used to augment pharmaceutical treatment. ${ }^{110}$

\section{Culturing}

Knowing when to culture a corneal lesion often times is not intuitive. Some advocate for culturing any corneal lesion, whereas the majority of ophthalmologists reserve culturing for lesions meeting specific criteria. ${ }^{111}$ According to the 2013 American Academy of Ophthalmology (AAO) Preferred Practice Patterns for Bacterial Keratitis, culturing only needs to be performed for ulcers that are deep, large, an atypical presentation, having questionable history or unresponsive to initial treatment. ${ }^{92}$ A recent survey, performed by Park et al, provides a glimpse of corneal culture procedures performed by ophthalmologists in the United States. ${ }^{111}$ Only $8.6 \%$ of ophthalmologists felt that it was necessary to always culture a lesion. ${ }^{111}$ Fifty-eight percent of the cases seen by corneal specialists are cultured versus $22 \%$ by noncorneal specialists. ${ }^{111}$ Overall, corneal specialists were more likely to culture, and all respondents were more likely to culture with unresponsive lesions, deep infiltrates, or atypical lesions. The practice patterns identified in the Park survey align well with the AAO corneal culturing guidelines.

Tertiary referral centers ${ }^{36,93,112}$ likely will have complete culturing supplies which include chocolate agar, blood agar, thioglycolate broth, brain-heart infusion broth, Sabouraud's dextrose agar, and nonnutrient agar with overlying Escherichia coli $^{113}$ (Table 4). For nontertiary referral centers, having access to transport swabs for culturing may be more prudent. The ESwab (Copan Diagnostics, Murrieta, CA, USA) uses a flocked nylon tip (Figure 1) which allows for increased fluid uptake and enhances specimen release. ${ }^{114}$ ESwabs have a shelf life of 18 months without refrigeration and they provide enhanced microbial uptake and release when compared with traditional swabs. ${ }^{115}$ ESwabs were compared with direct plating ${ }^{115}$ and found to provide positive cultures $69 \%$ of the time while direct plating yielded positive cultures $70 \%$ of the time.

Once a swab is used to collect microbes, the swab needs to be delivered to a microbiology lab for processing. 
Table 4 Culture yields obtained from the cornea and contact lens paraphernalia

\begin{tabular}{|c|c|c|c|c|}
\hline $\begin{array}{l}\text { Type of } \\
\text { microbe }\end{array}$ & $\begin{array}{l}\text { Positive cultures } \\
\text { from cornea (\%) }\end{array}$ & $\begin{array}{l}\text { Positive cultures } \\
\text { from lens case }(\%)\end{array}$ & $\begin{array}{l}\text { Positive cultures } \\
\text { from lenses (\%) }\end{array}$ & Preferred culture media \\
\hline \multirow[t]{4}{*}{ Bacteria } & $37^{123}-63^{120}$ & $80^{119}-83^{5}$ & $67^{118}-92^{119}$ & Chocolate agar \\
\hline & & & & Blood agar \\
\hline & & & & Thioglycollate broth \\
\hline & & & & Brain-heart infusion broth \\
\hline Fungal & $76^{93}-94^{8}$ & $70^{124}-84^{59}$ & $57^{124}$ & Sabouraud's dextrose agar \\
\hline Protozoan & $23^{93}-88^{87}$ & $23^{30}$ & $23^{30}$ & Nonnutrient agar with Escherichia coli \\
\hline
\end{tabular}

The ESwabs have been shown to provide viable specimens for several microbes even after 48 hours. ${ }^{116}$ Refrigeration of the sample improves the recovery viability for Neisseria gonorrhoeae at 48 hours. Pseudomonas, the most common isolate in contact lens-related $\mathrm{BK}$, can be recovered with or without refrigeration at 48 hours. ${ }^{116}$

Not all cultures yield positive results (Table 4), and the information obtained from cultures is not instantly available, so the clinician must begin treatment empirically. Once the culture is obtained, the topical therapy can be adjusted if the prescribed antimicrobial is ineffective against the offending microbe. If the corneal lesion is unresponsive to therapy, a referral to a corneal specialist should be initiated. The corneal specialist may need to obtain additional corneal scrapings for Gram stains or perform a corneal biopsy to be sent for culture and histopathological analysis. ${ }^{92}$ Gram stains obtained from corneal scrapings have been shown to be more sensitive than culturing for detecting fungus and protozoans in infectious keratitis cases. ${ }^{117}$ Scrapings should occur for both suspected FK, AK, and nonresolving BK. Specific to Acanthamoeba, scraping should occur, regardless of whether it is early or late in the disease process. ${ }^{85}$
In addition to culturing the cornea, contact lenses and their storage cases can provide positive cultures (Table 4). Positive culture yields from the contact lenses of patients with MK range from $67 \%{ }^{118}$ to $92 \%,{ }^{119}$ while positive yields from storage cases are as high as $80 \%-85 \% .{ }^{119,120}$ Culture positive cases are common in healthy contact lens wearers and do not always lead to MK. However, studies have shown a high species concordance between the cultures obtained from the corneas, contact lenses, and storage cases of patients with MK. Martins et al found that when the corneal cultures were positive, the species concordance with lens paraphernalia was $100 \%$ for FK, $80 \%$ for AK, and $74.5 \%$ for BK. ${ }^{121}$ Konda et al also demonstrated that when corneal cultures were negative, but microbes were obtained from the lens paraphernalia, that the isolated microbe likely was the infectious agent. ${ }^{119}$

\section{Microbiology}

Although culture yields vary among studies, often times the identified isolates are the same. For contact lens-related $\mathrm{BK}$, the most frequently isolated organism tends to be the Gram-negative species, P. aeruginosa ${ }^{5,10,122}$ (Table 5).

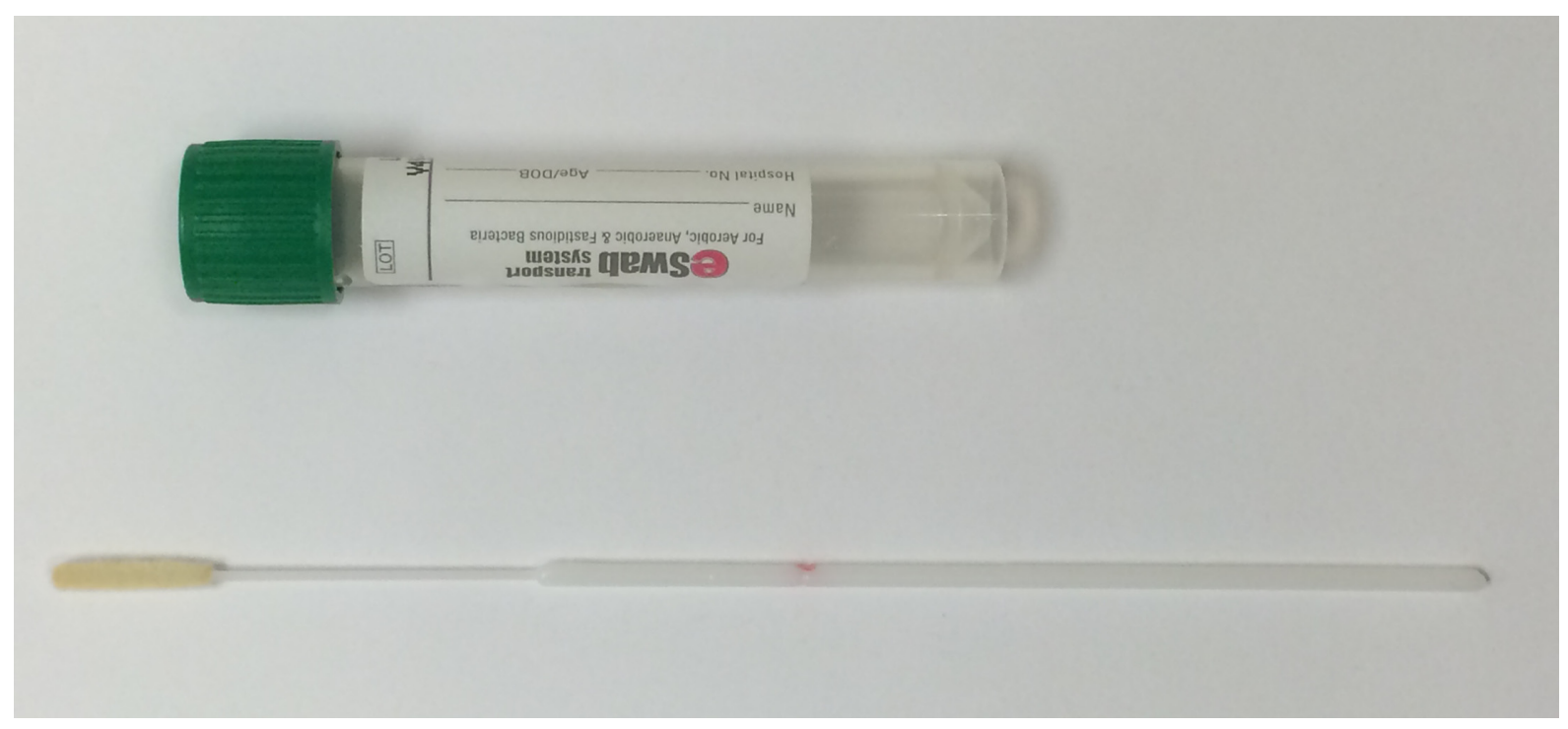

Figure I Copan E-swab. 
Table 5 Common microorganisms responsible for contact lensrelated microbial keratitis

\begin{tabular}{|c|c|}
\hline \multicolumn{2}{|c|}{$\begin{array}{l}\text { Common microorganisms associated with contact lens } \\
\text { microbial keratitis }\end{array}$} \\
\hline \multicolumn{2}{|l|}{ Bacteria $(71 \%-88 \%)^{8,119}$} \\
\hline \multicolumn{2}{|l|}{ Gram-positive } \\
\hline Staphylococcus spp." & $20 \%$ \\
\hline Coagulase-negative Staphylococci ${ }^{5,112,123}$ & $16.8 \%-49 \%$ \\
\hline Staphylococcus aureus 112 & $5.9 \%$ \\
\hline Staphylococcus epidermidis ${ }^{19}$ & $4.8 \%$ \\
\hline \multicolumn{2}{|l|}{ Gram-negative } \\
\hline Pseudomonas ${ }^{5,10,11,112,119,122,123}$ & $19 \%-73.5 \%$ \\
\hline Serratia ${ }^{5,11,119,122}$ & $4.8 \%-23 \%$ \\
\hline \multicolumn{2}{|l|}{ Fungal $(2.6 \%-5 \%)^{6,8,10,119}$} \\
\hline \multicolumn{2}{|l|}{ Filamentous } \\
\hline Fusarium 124 & $51 \%^{a}-68 \%$ \\
\hline Aspergillus ${ }^{124}$ & $9.2 \%$ a $-11 \%$ \\
\hline \multicolumn{2}{|l|}{ Yeast } \\
\hline Candida ${ }^{124}$ & $2 \%-12 \%^{a}$ \\
\hline \multicolumn{2}{|l|}{ Acanthamoeba $(0.9 \%-4 \%)^{8,119}$} \\
\hline Acanthamoeba castellaniii ${ }^{125,126}$ & $38 \%-66 \%$ \\
\hline Acanthamoeba polyphaga $a^{126}$ & $30 \%$ \\
\hline
\end{tabular}

Notes: The specific microbes that are in bold text indicate the most common species. Percentages do not add up to 100 as sterile keratitis cases can also be found. ${ }^{a}$ non-Fusarium outbreak ${ }^{124}$ (January 200I-September 2004 and October 2006-December 2007); 'Fusarium outbreak'"' (October 2004-September 2006).

Another commonly identified Gram-negative organism is Serratia spp. Rivaling Pseudomonas for the most commonly isolated bacteria associated with contact lens-related BK is the Gram-positive commensal organism, coagulase-negative Staphylococci. ${ }^{5,112,123}$ Gram-negative species tend to be more virulent and are associated with worse visual outcomes compared with Gram-positive microbes.?

FK accounts for approximately $5 \%$ of all contact lensrelated MK. ${ }^{6,10}$ The most common isolates are the filamentous organisms, Fusarium and Aspergillus. These two species account for between $62 \%$ and $77 \%$ of cases with the majority of cases due to Fusarium. ${ }^{124}$ Yeast, or molds, such as Candida spp, make up approximately $10 \%$ of contact lensrelated FK cases.

AK comprises between $0.9 \%$ and $4 \%$ of contact lensrelated MK. ${ }^{7,11,119}$ There are eight Acanthamoeba species that have been identified in patients with keratitis. The most common species related to keratitis are Acanthamoeba castellanii $^{125}$ and Acanthamoeba polyphaga. ${ }^{84,126}$ Although it is important to attempt to identify the offending amoeba, regardless of the species, the treatment will be the same. ${ }^{84}$

\section{Morbidity/visual outcomes/cost}

Of the three forms of MK, $\mathrm{AK}$ is the most worrisome and costly (Table 3 ). Keay et al estimate that the average cost of treatment (in 2006) was over US $\$ 5,500^{7}$ with the mean duration of treatment lasting between 140 days and 18 months. ${ }^{103,127,128}$ The worst visual outcomes tend to be cases with delayed diagnosis or those exposed to topical steroids. ${ }^{85,86}$ If diagnosed and treated early, visual outcomes are substantially better than a delayed diagnosis. ${ }^{85,86}$

About $30 \%$ of resolved contact lens FK result in visual acuity of worse than 20/30. ${ }^{129}$ In a multicenter analysis of FK in the United States, those with contact lens-related FK had a penetrating keratoplasty rate of approximately $17 \% .{ }^{124}$ Fortunately, if diagnosed early, there are effective medications, and time to resolution is approximately 1 month. ${ }^{130}$

BK tends to have less severe outcomes compared with AK or FK, but certainly can be visually devastating with one study showing a penetrating keratoplasty rate of approximately $13 \% .{ }^{131}$ Most studies show PK rates of less than $13 \%{ }^{9}$ and visual acuity loss (worse than 20/30) associated with contact lens-related BK has been reported to be around $14 \%{ }^{9}$

\section{Conclusion}

The incidence of contact lens-related MK has not significantly changed since 1989 . Some believe the incidence of MK, particularly AK is increasing. ${ }^{132,133}$ Eye care practitioners play an important role in diagnosing and managing cases of MK. While it is unlikely that an optometrist or a general ophthalmologist will be actively treating severe MK, it is important to recognize the clinical signs and symptoms early in the course of these diseases in order to refer for appropriate care quickly.

When fitting or evaluating contact lenses, the eye care practitioner must discuss the risks of contact lens wear and the need for proper lens replacement and disinfection with their patients. Improved and persistent patient education will hopefully help to decrease the incidence of MK.

\section{Disclosure}

The authors report no conflicts of interest in this work.

\section{References}

1. Nichols JJ. Contact lenses 2014. Contact Lens Spectrum. 2015; 30(1):22-27.

2. Dart JK, Stapleton F, Minassian D. Contact lenses and other risk factors in microbial keratitis. Lancet. 1991;338(8768):650-653.

3. Furlanetto RL, Andreo EG, Finotti IG, Arcieri ES, Ferreira MA, Rocha FJ. Epidemiology and etiologic diagnosis of infectious keratitis in Uberlandia, Brazil. Eur J Ophthalmol. 2010;20(3):498-503.

4. Shah VM, Tandon R, Satpathy G, et al. Randomized clinical study for comparative evaluation of fourth-generation fluoroquinolones with the combination of fortified antibiotics in the treatment of bacterial corneal ulcers. Cornea. 2010;29(7):751-757.

5. Bourcier T, Thomas F, Borderie V, Chaumeil C, Laroche L. Bacterial keratitis: predisposing factors, clinical and microbiological review of 300 cases. Br J Ophthalmol. 2003;87(7):834-838. 
6. Green M, Apel A, Stapleton F. Risk factors and causative organisms in microbial keratitis. Cornea. 2008;27(1):22-27.

7. Keay L, Edwards K, Naduvilath T, Forde K, Stapleton F. Factors affecting the morbidity of contact lens-related microbial keratitis: a population study. Invest Ophthalmol Vis Sci. 2006;47(10):4302-4308.

8. Poggio EC, Glynn RJ, Schein OD, et al. The incidence of ulcerative keratitis among users of daily-wear and extended-wear soft contact lenses. N Engl J Med. 1989;321(12):779-783.

9. Stapleton F, Keay L, Edwards K, et al. The incidence of contact lens-related microbial keratitis in Australia. Ophthalmology. 2008; 115(10):1655-1662.

10. Lam DS, Houang E, Fan DS, et al. Incidence and risk factors for microbial keratitis in Hong Kong: comparison with Europe and North America. Eye. 2002;16(5):608-618.

11. Cheng KH, Leung SL, Hoekman HW, et al. Incidence of contactlens-associated microbial keratitis and its related morbidity. Lancet. 1999;354(9174):181-185.

12. Seal DV, Kirkness CM, Bennett HG, Peterson M, Keratitis Study G. Acanthamoeba keratitis in Scotland: risk factors for contact lens wearers. Cont Lens Anterior Eye. 1999;22(2):58-68.

13. Dart JK, Radford CF, Minassian D, Verma S, Stapleton F. Risk factors for microbial keratitis with contemporary contact lenses: a case-control study. Ophthalmology. 2008;115(10):1647-1654, 1654. e1641-e1643.

14. Schein OD, McNally JJ, Katz J, et al. The incidence of microbial keratitis among wearers of a 30-day silicone hydrogel extended-wear contact lens. Ophthalmology. 2005;112(12):2172-2179.

15. Szczotka-Flynn L, Diaz M. Risk of corneal inflammatory events with silicone hydrogel and low dk hydrogel extended contact lens wear: a meta-analysis. Optom Vis Sci. 2007;84(4):247-256.

16. Stapleton F, Keay L, Edwards K, Holden B. The epidemiology of microbial keratitis with silicone hydrogel contact lenses. Eye Contact Lens. 2013;39(1):79-85.

17. Robertson DM. The effects of silicone hydrogel lens wear on the corneal epithelium and risk for microbial keratitis. Eye Contact Lens. 2013; 39(1):67-72.

18. Bullimore MA, Sinnott LT, Jones-Jordan LA. The risk of microbial keratitis with overnight corneal reshaping lenses. Optom Vis Sci. 2013; 90(9):937-944.

19. Chan TC, Li EY, Wong VW, Jhanji V. Orthokeratology-associated infectious keratitis in a tertiary care eye hospital in Hong Kong. Am J Ophthalmol. 2014;158(6):1130-1135. e1132.

20. Watt KG, Swarbrick HA. Trends in microbial keratitis associated with orthokeratology. Eye Contact Lens. 2007;33(6 Pt 2):373-377; discussion 382.

21. Gray TB, Cursons RT, Sherwan JF, Rose PR. Acanthamoeba, bacterial, and fungal contamination of contact lens storage cases. Br JOphthalmol. 1995;79(6):601-605.

22. Houang E, Lam D, Fan D, Seal D. Microbial keratitis in Hong Kong: relationship to climate, environment and contact-lens disinfection. Trans R Soc Trop Med Hyg. 2001;95(4):361-367.

23. Morgan PB, Efron N, Brennan NA, Hill EA, Raynor MK, Tullo AB. Risk factors for the development of corneal infiltrative events associated with contact lens wear. Invest Ophthalmol Vis Sci. 2005;46(9):3136-3143.

24. Stapleton F, Dart JK, Minassian D. Risk factors with contact lens related suppurative keratitis. CLAO J. 1993;19(4):204-210.

25. Carnt NA, Willcox MD, Hau S, et al. Immune defense single nucleotide polymorphisms and recruitment strategies associated with contact lens keratitis. Ophthalmology. 2012;119(10):1997-2002.

26. Carnt NA, Willcox MD, Hau S, et al. Association of single nucleotide polymorphisms of interleukins-1beta, -6 , and $-12 \mathrm{~B}$ with contact lens keratitis susceptibility and severity. Ophthalmology. 2012; 119(7):1320-1327.

27. Sauer A, Bourcier T, French Study Group for Contact Lenses Related Microbial K. Microbial keratitis as a foreseeable complication of cosmetic contact lenses: a prospective study. Acta Ophthalmol. 2011; 89(5):e439-e442.
28. Radford CF, Bacon AS, Dart JK, Minassian DC. Risk factors for acanthamoeba keratitis in contact lens users: a case-control study. $B M J$. 1995;310(6994):1567-1570.

29. Chang DC, Grant GB, O'Donnell K, et al. Multistate outbreak of Fusarium keratitis associated with use of a contact lens solution. JAMA. 2006;296(8):953-963.

30. Verani JR, Lorick SA, Yoder JS, et al. National outbreak of Acanthamoeba keratitis associated with use of a contact lens solution, United States. Emerg Infect Dis. 2009;15(8):1236-1242.

31. Nielsen SE, Nielsen E, Julian HO, et al. Incidence and clinical characteristics of fungal keratitis in a Danish population from 2000 to 2013. Acta Ophthalmol. 2015;93(1):54-58.

32. Bharathi MJ, Ramakrishnan R, Meenakshi R, Padmavathy S, Shivakumar C, Srinivasan M. Microbial keratitis in South India: influence of risk factors, climate, and geographical variation. Ophthalmic Epidemiol. 2007;14(2):61-69.

33. Tanure MA, Cohen EJ, Sudesh S, Rapuano CJ, Laibson PR. Spectrum of fungal keratitis at Wills Eye Hospital, Philadelphia, Pennsylvania. Cornea. 2000;19(3):307-312.

34. Ritterband DC, Seedor JA, Shah MK, Koplin RS, McCormick SA. Fungal keratitis at the New York eye and ear infirmary. Cornea. 2006;25(3):264-267.

35. CDC.gov [homepage on the Internet]. Parasites - Acanthamoeba Granulomatous Amebic Encephalitis (GAE); Keratitis [updated August 24, 2012]. Available from: http://www.cdc.gov/parasites/acanthamoeba/ epi.html. Accessed June 24, 2015.

36. Mascarenhas J, Lalitha P, Prajna NV, et al. Acanthamoeba, fungal, and bacterial keratitis: a comparison of risk factors and clinical features. Am J Ophthalmol. 2014;157(1):56-62.

37. Whiting MA, Raynor MK, Morgan PB, Galloway P, Tole DM, Tullo A. Continuous wear silicone hydrogel contact lenses and microbial keratitis. Eye. 2004;18(9):935-937.

38. Fleiszig SM, McNamara NA, Evans DJ. The tear film and defense against infection. Adv Exp Med Biol. 2002;506(Pt A): 523-530.

39. Flanagan JL, Willcox MD. Role of lactoferrin in the tear film. Biochimie. 2009;91(1):35-43.

40. Evans DJ, Fleiszig SM. Why does the healthy cornea resist Pseudomonas aeruginosa infection? Am J Ophthalmol. 2013;155(6):961-970.e962.

41. Alarcon I, Tam C, Mun JJ, LeDue J, Evans DJ, Fleiszig SM. Factors impacting corneal epithelial barrier function against $P$ seudomonas aeruginosa traversal. Invest Ophthalmol Vis Sci. 2011;52(3):1368-1377.

42. Tam C, Mun JJ, Evans DJ, Fleiszig SM. The impact of inoculation parameters on the pathogenesis of contact lens-related infectious keratitis. Invest Ophthalmol Vis Sci. 2010;51(6):3100-3106.

43. Ladage PM, Jester JV, Petroll WM, Bergmanson JP, Cavanagh HD. Vertical movement of epithelial basal cells toward the corneal surface during use of extended-wear contact lenses. Invest Ophthalmol Vis Sci. 2003;44(3):1056-1063.

44. Cavanagh HD. The effects of low- and hyper-Dk contact lenses on corneal epithelial homeostasis. Ophthalmol Clin North Am. 2003;16(3):311-325.

45. Ren DH, Petroll WM, Jester JV, Ho-Fan J, Cavanagh HD. Short-term hypoxia downregulates epithelial cell desquamation in vivo, but does not increase Pseudomonas aeruginosa adherence to exfoliated human corneal epithelial cells. CLAO J. 1999;25(2):73-79.

46. Cavanagh HD, Ladage PM, Li SL, et al. Effects of daily and overnight wear of a novel hyper oxygen-transmissible soft contact lens on bacterial binding and corneal epithelium: a 13-month clinical trial. Ophthalmology. 2002;109(11):1957-1969.

47. Imayasu M, Petroll WM, Jester JV, Patel SK, Ohashi J, Cavanagh HD. The relation between contact lens oxygen transmissibility and binding of Pseudomonas aeruginosa to the cornea after overnight wear. Ophthalmology. 1994;101(2):371-388.

48. Fleiszig SM, Evans DJ. Contact lens infections: can they ever be eradicated? Eye Contact Lens. 2003;29(1 Supp1):S67-S71; discussion S83-S84, S192-S194. 
49. Stapleton F, Carnt N. Contact lens-related microbial keratitis: how have epidemiology and genetics helped us with pathogenesis and prophylaxis. Eye. 2012;26(2):185-193.

50. Robertson DM, Petroll WM, Jester JV, Cavanagh HD. The role of contact lens type, oxygen transmission, and care-related solutions in mediating epithelial homeostasis and pseudomonas binding to corneal cells: an overview. Eye Contact Lens. 2007;33(6 Pt 2):394-398; discussion 399-400.

51. Fletcher EL, Fleiszig SM, Brennan NA. Lipopolysaccharide in adherence of Pseudomonas aeruginosa to the cornea and contact lenses. Invest Ophthalmol Vis Sci. 1993;34(6):1930-1936.

52. Sato H, Frank DW. ExoU is a potent intracellular phospholipase. Mol Microbiol. 2004;53(5):1279-1290.

53. Choy MH, Stapleton F, Willcox MD, Zhu H. Comparison of virulence factors in Pseudomonas aeruginosa strains isolated from contact lensand non-contact lens-related keratitis. JMed Microbiol. 2008;57(Pt 12): 1539-1546.

54. Borkar DS, Fleiszig SM, Leong C, et al. Association between cytotoxic and invasive Pseudomonas aeruginosa and clinical outcomes in bacterial keratitis. JAMA Ophthalmol. 2013;131(2):147-153.

55. Tang H, Kays M, Prince A. Role of Pseudomonas aeruginosa pili in acute pulmonary infection. Infect Immun. 1995;63(4):1278-1285.

56. Feldman M, Bryan R, Rajan S, et al. Role of flagella in pathogenesis of Pseudomonas aeruginosa pulmonary infection. Infect Immun. 1998;66(1):43-51.

57. Kung VL, Ozer EA, Hauser AR. The accessory genome of Pseudomonas aeruginosa. Microbiol Mol Biol Rev. 2010;74(4):621-641.

58. Dantas G, Sommer MO, Oluwasegun RD, Church GM. Bacteria subsisting on antibiotics. Science. 2008;320(5872):100-103.

59. Gower EW, Keay LJ, Oechsler RA, et al. Trends in fungal keratitis in the United States, 2001 to 2007. Ophthalmology. 2010; 117(12):2263-2267.

60. Zhang S, Ahearn DG, Stulting RD, et al. Differences among strains of the Fusarium oxysporum $-F$. solani complexes in their penetration of hydrogel contact lenses and subsequent susceptibility to multipurpose contact lens disinfection solutions. Cornea. 2007;26(10): 1249-1254.

61. Sun Y, Chandra J, Mukherjee P, Szczotka-Flynn L, Ghannoum MA, Pearlman E. A murine model of contact lens-associated fusarium keratitis. Invest Ophthalmol Vis Sci. 2010;51(3):1511-1516.

62. Thomas PA. Fungal infections of the cornea. Eye. 2003;17(8): 852-862.

63. Leal SM Jr, Pearlman E. The role of cytokines and pathogen recognition molecules in fungal keratitis - insights from human disease and animal models. Cytokine. 2012;58(1):107-111.

64. Hu J, Wang Y, Xie L. Potential role of macrophages in experimental keratomycosis. Invest Ophthalmol Vis Sci. 2009;50(5):2087-2094.

65. Acanthamoeba Keratitis FAQs http://www.cdc.gov/parasites/ acanthamoeba/gen_info/acanthamoeba_keratitis.html. Accessed November 18, 2015.

66. Walochnik J, Scheik1 U, Haller-Schober EM. Twenty years of acanthamoeba diagnostics in Austria. J Eukaryot Microbiol. 2015; 62(1):3-11.

67. Khan NA. Acanthamoeba: biology and increasing importance in human health. FEMS Microbiol Rev. 2006;30(4):564-595.

68. Omana-Molina MA, Gonzalez-Robles A, Salazar-Villatoro L, et al. Silicone hydrogel contact lenses surface promote Acanthamoeba castellanii trophozoites adherence: qualitative and quantitative analysis. Eye Contact Lens. 2014;40(3):132-139.

69. Lorenzo-Morales J, Khan NA, Walochnik J. An update on Acanthamoeba keratitis: diagnosis, pathogenesis and treatment. Parasite. 2015;22:10

70. Garate M, Cao Z, Bateman E, Panjwani N. Cloning and characterization of a novel mannose-binding protein of Acanthamoeba. J Biol Chem. 2004;279(28):29849-22956.

71. Klotz SA, Misra RP, Butrus SI. Contact lens wear enhances adherence of Pseudomonas aeruginosa and binding of lectins to the cornea. Cornea. 1990;9(3):266-270.
72. Alizadeh H, Neelam S, Hurt M, Niederkorn JY. Role of contact lens wear, bacterial flora, and mannose-induced pathogenic protease in the pathogenesis of amoebic keratitis. Infect Immun. 2005;73(2): 1061-1068.

73. Panjwani N. Pathogenesis of acanthamoeba keratitis. Ocul Surf. 2010;8(2):70-79.

74. Clarke DW, Niederkorn JY. The pathophysiology of Acanthamoeba keratitis. Trends Parasitol. 2006;22(4):175-180.

75. Clarke DW, Alizadeh H, Niederkorn JY. Failure of Acanthamoeba castellanii to produce intraocular infections. Invest Ophthalmol Vis Sci. 2005;46(7):2472-2478.

76. Lloyd D. Encystment in Acanthamoeba castellanii: a review. Exp Parastiol. 2014;145 Suppl:S20-S27.

77. Yang YF, Matheson M, Dart JK, Cree IA. Persistence of acanthamoeba antigen following acanthamoeba keratitis. Br J Ophthalmol. 2001; 85(3):277-280.

78. Robboy MW, Comstock TL, Kalsow CM. Contact lens-associated corneal infiltrates. Eye Contact Lens. 2003;29(3):146-154.

79. Stein RM, Clinch TE, Cohen EJ, Genvert GI, Arentsen JJ, Laibson PR. Infected vs sterile corneal infiltrates in contact lens wearers. Am J Ophthalmol. 1988;105(6):632-636.

80. Klotz SA, Penn CC, Negvesky GJ, Butrus SI. Fungal and parasitic infections of the eye. Clin Microbiol Rev. 2000;13(4):662-685.

81. Thomas PA, Leck AK, Myatt M. Characteristic clinical features as an aid to the diagnosis of suppurative keratitis caused by filamentous fungi. Br J Ophthalmol. 2005;89(12):1554-1558.

82. Hu FR, Huang WJ, Huang SF. Clinicopathologic study of satellite lesions in nontuberculous mycobacterial keratitis. Jpn J Ophthalmol. 1998;42(2):115-118.

83. Wilhelmus KR, Jones DB. Curvularia keratitis. Trans Am Ophthalmol Soc. 2001;99:111-130; discussion 130-132.

84. Dart JK, Saw VP, Kilvington S. Acanthamoeba keratitis: diagnosis and treatment update 2009. Am J Ophthalmol. 2009;148(4):487-499. e482.

85. Qian Y, Meisler DM, Langston RH, Jeng BH. Clinical experience with Acanthamoeba keratitis at the Cole eye institute, 1999-2008. Cornea. 2010;29(9):1016-1021.

86. Ross J, Roy SL, Mathers WD, et al. Clinical characteristics of Acanthamoeba keratitis infections in 28 states, 2008 to 2011. Cornea. 2014;33(2):161-168.

87. Hau SC, Dart JK, Vesaluoma M, et al. Diagnostic accuracy of microbial keratitis with in vivo scanning laser confocal microscopy. $\mathrm{Br} \mathrm{J} \mathrm{Oph}$ thalmol. 2010;94(8):982-987.

88. Tu EY, Joslin CE, Sugar J, Booton GC, Shoff ME, Fuerst PA. The relative value of confocal microscopy and superficial corneal scrapings in the diagnosis of Acanthamoeba keratitis. Cornea. 2008;27(7): 764-772.

89. Constantinou M, Daniell M, Snibson GR, Vu HT, Taylor HR. Clinical efficacy of moxifloxacin in the treatment of bacterial keratitis: a randomized clinical trial. Ophthalmology. 2007;114(9):1622-1629.

90. Gangopadhyay N, Daniell M, Weih L, Taylor HR. Fluoroquinolone and fortified antibiotics for treating bacterial corneal ulcers. $\mathrm{Br} J$ Ophthalmol. 2000;84(4):378-384.

91. Khokhar S, Sindhu N, Mirdha BR. Comparison of topical $0.3 \%$ ofloxacin to fortified tobramycin-cefazolin in the therapy of bacterial keratitis. Infection. 2000;28(3):149-152.

92. American Academy of Ophthalmology Cornea/External Disease Panel. Preferred Practice Pattern Guidelines. Bacterial Keratitis. San Francisco, CA: American Academy of Ophthalmology; 2013. Available from: http://www.aao.org/ppp. Accessed November 18, 2015.

93. Ni N, Nam EM, Hammersmith KM, et al. Seasonal, geographic, and antimicrobial resistance patterns in microbial keratitis: 4-year experience in eastern Pennsylvania. Cornea. 2015;34(3):296-302.

94. Asbell PA, Sahm DF, Shaw M, Draghi DC, Brown NP. Increasing prevalence of methicillin resistance in serious ocular infections caused by Staphylococcus aureus in the United States: 2000 to 2005. J Cat Refract Surg. 2008;34(5):814-818. 
95. Sanders ME, Moore QC 3rd, Norcross EW, et al. Comparison of besifloxacin, gatifloxacin, and moxifloxacin against strains of Pseudomonas aeruginosa with different quinolone susceptibility patterns in a rabbit model of keratitis. Cornea. 2011;30(1):83-90.

96. Sanfilippo CM, Morrissey I, Janes R, Morris TW. Surveillance of the activity of aminoglycosides and fluoroquinolones against ophthalmic pathogens from Europe in 2010-2011. Curr Eye Res. 2015:1-9.

97. Elsahn AF, Yildiz EH, Jungkind DL, et al. In vitro susceptibility patterns of methicillin-resistant Staphylococcus aureus and coagulasenegative Staphylococcus corneal isolates to antibiotics. Cornea. 2010;29(10):1131-1135.

98. Rattanatam T, Heng WJ, Rapuano CJ, Laibson PR, Cohen EJ. Trends in contact lens-related corneal ulcers. Cornea. 2001;20(3):290-294.

99. Srinivasan M, Mascarenhas J, Rajaraman R, et al. Corticosteroids for bacterial keratitis: the Steroids for Corneal Ulcers Trial (SCUT). Arch Ophthalmol. 2012;130(2):143-150.

100. Loh RS, Chan CM, Ti SE, Lim L, Chan KS, Tan DT. Emerging prevalence of microsporidial keratitis in Singapore: epidemiology, clinical features, and management. Ophthalmology. 2009;116(12):2348-2353

101. Ou JI, Acharya NR. Epidemiology and treatment of fungal corneal ulcers. Int Ophthalmol Clin. 2007;47(3):7-16.

102. Prajna NV, Krishnan T, Mascarenhas J, et al. The mycotic ulcer treatment trial: a randomized trial comparing natamycin vs voriconazole. JAMA Ophthalmol. 2013;131(4):422-429.

103. Chin J, Young AL, Hui M, Jhanji V. Acanthamoeba keratitis: 10-year study at a tertiary eye care center in Hong Kong. Cont Lens Anterior Eye. 2015;38(2):99-103.

104. Oldenburg CE, Acharya NR, Tu EY, et al. Practice patterns and opinions in the treatment of acanthamoeba keratitis. Cornea. 2011; 30(12):1363-1368.

105. Tu EY, Joslin CE, Shoff ME. Successful treatment of chronic stromal acanthamoeba keratitis with oral voriconazole monotherapy. Cornea. 2010;29(9):1066-1068.

106. Kitzmann AS, Goins KM, Sutphin JE, Wagoner MD. Keratoplasty for treatment of Acanthamoeba keratitis. Ophthalmology. 2009; 116(5):864-869.

107. Iseli HP, Thiel MA, Hafezi F, Kampmeier J, Seiler T. Ultraviolet A/ riboflavin corneal cross-linking for infectious keratitis associated with corneal melts. Cornea. 2008;27(5):590-594.

108. Martins SA, Combs JC, Noguera G, et al. Antimicrobial efficacy of riboflavin/UVA combination $(365 \mathrm{~nm})$ in vitro for bacterial and fungal isolates: a potential new treatment for infectious keratitis. Invest Ophthalmol Vis Sci. 2008;49(8):3402-3408.

109. Moren H, Malmsjo M, Mortensen J, Ohrstrom A. Riboflavin and ultraviolet a collagen crosslinking of the cornea for the treatment of keratitis. Cornea. 2010;29(1):102-104.

110. Barequet IS, Habot-Wilner Z, Keller N, et al. Effect of amniotic membrane transplantation on the healing of bacterial keratitis. Invest Ophthalmol Vis Sci. 2008;49(1):163-167.

111. Park J, Lee KM, Zhou H, et al. Community practice patterns for bacterial corneal ulcer evaluation and treatment. Eye Contact Lens. 2015; 41(1):12-18.

112. Yildiz EH, Airiani S, Hammersmith KM, et al. Trends in contact lens-related corneal ulcers at a tertiary referral center. Cornea. 2012 31(10):1097-1102.

113. Graffi S, Peretz A, Jabaly H, Naftali M. Acanthamoeba keratitis. Isr Med Assoc J. 2013;15(4):182-185.

114. Osterblad M, Jarvinen H, Lonnqvist K, et al. Evaluation of a new cellulose sponge-tipped swab for microbiological sampling: a laboratory and clinical investigation. J Clin Microbiol. 2003;41(5):1894-1900.
115. Pakzad-Vaezi K, Levasseur SD, Schendel S, et al. The corneal ulcer one-touch study: a simplified microbiological specimen collection method. Am J Ophthalmol. 2015;159(1):37-43. e31.

116. Van Horn KG, Audette CD, Sebeck D, Tucker KA. Comparison of the Copan ESwab system with two Amies agar swab transport systems for maintenance of microorganism viability. J Clin Microbiol. 2008;46(5):1655-1658.

117. Goldschmidt P, Rostane H, Saint-Jean C, et al. Effects of topical anaesthetics and fluorescein on the real-time PCR used for the diagnosis of Herpes viruses and Acanthamoeba keratitis. Br J Ophthalmol. 2006;90(11):1354-1356.

118. Das S, Sheorey H, Taylor HR, Vajpayee RB. Association between cultures of contact lens and corneal scraping in contact lens related microbial keratitis. Arch Ophthalmol. 2007;125(9):1182-1185.

119. Konda N, Motukupally SR, Garg P, Sharma S, Ali MH, Willcox MD. Microbial analyses of contact lens-associated microbial keratitis. Optom Vis Sci. 2014;91(1):47-53.

120. McLaughlin-Borlace L, Stapleton F, Matheson M, Dart JK. Bacterial biofilm on contact lenses and lens storage cases in wearers with microbial keratitis. J Appl Microbiol. 1998;84(5):827-838.

121. Martins EN, Farah ME, Alvarenga LS, Yu MC, Hoflin-Lima AL. Infectious keratitis: correlation between corneal and contact lens cultures. CLAO J. 2002;28(3):146-148.

122. Mah-Sadorra JH, Yavuz SG, Najjar DM, Laibson PR, Rapuano CJ, Cohen EJ. Trends in contact lens-related corneal ulcers. Cornea. 2005;24(1):51-58.

123. Musa F, Tailor R, Gao A, Hutley E, Rauz S, Scott RA. Contact lensrelated microbial keratitis in deployed British military personnel. $\mathrm{Br}$ J Ophthalmol. 2010;94(8):988-993.

124. Keay LJ, Gower EW, Iovieno A, et al. Clinical and microbiological characteristics of fungal keratitis in the United States, 2001-2007: a multicenter study. Ophthalmology. 2011;118(5):920-926.

125. Mathers WD, Nelson SE, Lane JL, Wilson ME, Allen RC, Folberg R. Confirmation of confocal microscopy diagnosis of Acanthamoeba keratitis using polymerase chain reaction analysis. Arch Ophthalmol. 2000;118(2):178-183.

126. CDC. Acanthamoeba keratitis associated with contact lenses United States. MMWR Morb Mortal Wkly Rep. 1986;35(25): 405-408

127. Butler TK, Males JJ, Robinson LP, et al. Six-year review of Acanthamoeba keratitis in New South Wales, Australia: 1997-2002. Clin Exp Ophthalmol. 2005;33(1):41-46.

128. Radford CF, Lehmann OJ, Dart JK. Acanthamoeba keratitis: multicentre survey in England 1992-1996. National Acanthamoeba Keratitis Study Group. Br J Ophthalmol. 1998;82(12):1387-1392.

129. Iyer SA, Tuli SS, Wagoner RC. Fungal keratitis: emerging trends and treatment outcomes. Eye Contact Lens. 2006;32(6):267-271.

130. Prajna NV, Srinivasan M, Lalitha P, et al. Differences in clinical outcomes in keratitis due to fungus and bacteria. JAMA Ophthalmol. 2013;131(8):1088-1089.

131. Miedziak AI, Miller MR, Rapuano CJ, Laibson PR, Cohen EJ. Risk factors in microbial keratitis leading to penetrating keratoplasty. Ophthalmology. 1999;106(6):1166-1170; discussion 1171.

132. Tu EY. Acanthamoeba keratitis: a new normal. Am J Ophthalmol. 2014;158(3):417-419.

133. Yoder JS, Verani J, Heidman N, et al. Acanthamoeba keratitis: the persistence of cases following a multistate outbreak. Ophthalmic Epidemiol. 2012;19(4):221-225. 


\section{Publish your work in this journal}

Clinical Optometry is an international, peer-reviewed, open access journal publishing original research, basic science, clinical and epidemiological studies, reviews and evaluations on clinical optometry. All aspects of patient care are addressed within the journal as well as the practice of optometry including economic and business analyses. Basic and clinical

Submit your manuscript here: http://www.dovepress.com/clinical-optometry-journal research papers are published that cover all aspects of optics, refraction and its application to the theory and practice of optometry. The manuscript management system is completely online and includes a very quick and fair peer-review system, which is all easy to use. Visit http://www.dovepress. com/testimonials.php to read real quotes from published authors. 